\title{
O ENSINO AGRÍCOLA NO MARANHÃO IMPERIAL
}

\author{
César Augusto Castro \\ Universidade Federal do Maranhão - UFMA \\ ccampin@terra.com.br
}

\section{RESUMO}

Neste artigo, tratamos do ensino agrícola no Maranhão Império oferecido pela Escola do Cutim, instituição criada em 1859 com a finalidade de recolher e educar crianças pobres e desvalidas. Descrevem-se os processos de ensino adotados através do método aratório, do ensino do ofício carpinteiro e do ferreiro, da criação de animais domésticos, e do plantio, colheita e beneficiamento dos produtos agrícolas (tais como: açúcar, arroz milho e algodão). Trata-se dos diferentes investimentos da Província para a criação e manutenção da escola, como a contratação de professores e a importação de produtos, sementes e animais de várias partes do Brasil, Estados Unidos e França. Conclui-se que a Escola Agrícola do Cutim foi um empreendimento público levado a efeito no Maranhão oitocentista com o objetivo de formar mão de obra para ordenar e regular a vida de meninos oriundos da parcela menos favorecida da sociedade, ao mesmo tempo em que pretendia aprimorar as formas de produção agrícola que contribuíram para o desenvolvimento econômico do Maranhão na época.

Palavras-chave: Ensino agrícola, Maranhão Império, Instrução Pública.

\section{THE AGRICULTURAL TEACHING IN THE IMPERIAL MARANHÃO: A HISTORY OF THE SCHOOL OF THE CUTIM}

\begin{abstract}
In this article, we treat the agricultural teaching in Maranhão Empire offered by the School of the Cutim, institution created in 1859 with the finality of retiring and educating poor and helpless children. The processes of teaching are described through the plowing method, the teaching of the blacksmith and carpenter's trade, the creation of domestic animals, and finally, the planting and improvement of the agricultural products (such as: sugar, rice, corn and cotton). We study as well the different investments of the Province for the creation and maintenance of the School, like the teachers' employment and the import of products arrived from several parts of Brazil, the United States and France. We conclude that Agricultural School of the Cutim was a public undertaking in Maranhão in the XIX century. Besides, It had the objective to form labour to order and to regulate the life of boys originating from the least favored piece of the society, at the same time in which it was intending to perfect the forms of agricultural production that contributed to the economical development of the Maranhão in the time.
\end{abstract}

Keywords: Agricultural teaching, Maranhão Empire, Public Education.

Este trabalho insere-se dentro de um conjunto de investigações em andamento sobre a história da infância e das instituições escolares desenvolvidos pelo Núcleo de Estudo e Documentação em História da Educação e da Leitura (NEDHEL, da Universidade Federal do 
Maranhão), cujas pesquisas privilegiam o século XIX, por ser o período em que há maior carência de estudos sistematizados no Estado (CASTRO, 2009).

No conjunto de instituições escolares criadas na Província do Maranhão, direcionamos o nosso olhar para aquelas que tinham a finalidade de recolher e prestar assistência a crianças pobres e desvalidas, oferecendo-lhes o ensino das primeiras letras e uma formação profissional.

Esse direcionamento vem ao encontro de um conjunto de investigações brasileiras que procura desvelar o universo da Educação Infantil, ainda relativamente lacunar na historiografia da educação quando comparado a outras temáticas (KULHEMAN JUNIOR, 1998). De igual modo, a formação profissional tem sido um assunto quase ignorado pelos historiadores da educação que se preocupam em explicar a escolarização das elites e o trabalho intelectual (CASTRO, 2007; CUNHA, 1976).

Dentre as instituições criadas no Maranhão no período, localizamos vasta documentação que contribuiu para o resgate histórico desses estabelecimentos educacionais: textos manuscritos; artigos publicados na imprensa periódica; relatórios e falas dos presidentes de província; e fontes legislativas sobre a Casa dos Educandos Artífices, Escola de Aprendizes Marinheiros, Recolhimento de Nossa Senhora de Anunciação e Remédios, Asilo de Santa Teresa e a Escola de Aprendizes Agrícolas.

Em relação às fontes secundárias, destacamos o inventário de Mello (2004), principal instrumento bibliográfico sobre o movimento das artes e ofícios no Maranhão do Império à Primeira República; as demais obras tratam dessas instituições de forma horizontalizada, como classifica Silva ${ }^{1}$.

A criação dessas instituições vinha ao encontro de uma série de ações do governo provincial para atender a parcelas da população (meninos e meninas) que ocupavam áreas marginais da sociedade, tais como os vadios, os abandonados de sorte, os pobres e desvalidos. $\mathrm{Na}$ concepção de Reis (2007), essas "obras de caridade" foram uma das causas do empobrecimento da Província que as privilegiava em detrimento da indústria, do comércio e da lavoura. Para ele, os gastos públicos com a "os pobres maranhenses" ultrapassavam todas as outras despesas da Província que incluíam, além das instituições citadas, a Santa Casa da Misericórdia, os Lazaretos e a Casa dos Expostos.

A Casa dos Educandos Artífices foi criada em 1841. Dentre todas as instituições de recolhimento e educação profissional, foi a que teve um ciclo mais longo, encerrando suas atividades na República. Essa instituição tinha como objetivo formar sapateiros, alfaiates, carpinteiros, além de outras artes e ofícios. A Escola de Aprendizes Marinheiros tratava de formar mão-de-obra para atender à expansão da navegação pelos rios e litoral maranhense. O Asilo de Santa Teresa e o Recolhimento destinavam-se a preparar moças para as atividades domésticas.

Por seu turno, a Escola Agrícola do Cutim centrava-se na formação de mão-de-obra para as atividades agropecuárias. Essa instituição constitui-se o foco do presente trabalho, que se insere "aos poucos estudos de história da educação no Brasil que se dedicam ao ensino agrícola" (NASCIMENTO, 2008, p. 3).

Para Nascimento (2008), tais estudos seguem duas tendências. A primeira visa compreender os processos de formação de mão-de-obra, já a segunda, visa elucidar a delinquência juvenil numa educação correcional "por meio da vida no campo com a predominância da reclusão e da ênfase nos aspectos disciplinares" que incluía desde a repreensão individual ou pública, até a prisão no interior das escolas. Esse era um modelo de ordenação e disciplina transposto das organizações militares para essas instituições de recolhimento e de educação profissional. 
As crianças atendidas por essas instituições tinham praticamente a mesma origem: eram pobres e desvalidas, oriundas da casa dos expostos, de famílias sem condições de criálas, abandonadas nas ruas pelos pais ou tutores. Nesse sentido, a aprendizagem de um ofício mecânico, agrícola e industrial - seria uma maneira de higienização social e de garantia de um conjunto de atividades que a elite intelectual, branca e residente nos faustos casarões necessitava para manter seus privilégios domésticos e sociais. Para isso, a educação destinada a esses "órfãos deveria habilitá-los a terem um meio de vida em menor espaço de tempo (OLIVEIRA, 2003, p.183). Para Oliveira (2003), esse modelo de instrução deveria ser sólida e orientada para o amor ao trabalho, concebido como redenção e sacerdócio.

Como forma de garantir essa aprendizagem, um conjunto de saberes e práticas se faziam necessárias. As primeiras letras constituíam a base para a apreensão de conhecimentos específicos, como os relativos à topografia, à geometria, à mecânica e ao desenho aplicado às artes, dentre outras tantas que compunham o currículo escolar dessas instituições.

Duas condições são necessárias para uma conveniente organização do ensino profissional de modo a satisfazer o seu grande desiderato - uma instrução primária regularmente desenvolvida e uma instrução média, que desenvolvendo as faculdades do espírito, prepara e facilita a escolha das profissões pelo desenvolvimento das aptidões, e sobre um vasto sistema de ensino geral e pratico habilita as inteligências para dedicarem-se às especialidades do comércio, da indústria e agricultura, segundo as necessidades (BARROSO, 1867, p. 127).

Não há registro sistematizado sobre a Escola Agrícola do Cutim. As fontes primárias manuscritas localizadas no arquivo do estado do Maranhão, apesar de apresentarem um estado avançado de deteriorização, foram as principais referências para a escrita deste trabalho.

Barroso (1867), ao citar a Escola Agrícola do Cutim na obra A Instrução Pública no Brasil, afirma que pouco ou nenhum resultado havia sido colhido desde a sua criação. Outras fontes são o trabalho de Rosa (1980) e Mesquita (1987). Por último, Marques (1970), no Dicionário Histórico- Geográfico da Província do Maranhão, não nos permite tecer o seu ciclo de vida por conter alguns equívocos históricos na sua cronologia e descrição dos fatos.

A criação dessa escola foi proposta em 1859 pelo presidente da Província João da Silva Lustosa da Cunha Paranaguá com as seguintes finalidades: a) ensinar à mocidade pobre maranhense a agricultura prática e teórica utilizada em regiões mais desenvolvidas da Europa e Estados Unidos; b) desenvolver experiências e ensaios para a melhoria do sistema agrícola centralizado no uso de mão-de-obra escrava ou de trabalhadores assalariados; c) formar um centro de observações e demonstrações práticas para a instrução de lavradores como uma maneira de aumentar a exportação dos produtos agrícolas; e d) atender "abandonados de sorte", mediante uma educação profissional que garantisse a melhoria das culturas agrícolas da Província. De acordo com Rodrigues (1959, p. 26), Paranaguá teria sido o "primeiro administrador brasileiro que teve a fortuna e a glória de fundar e inaugurar na Província e no Império a primeira colônia prática de aprendizes agrícolas pelo systema aratório"

Segundo Paranaguá, a educação aos pobres e desvalidos seria o papel central da instituição para mantê-los afastados dos vícios e da criminalidade, por meio de "uma arte eminentemente útil, a primeira no nosso país, buscando assim os fundamentos da reforma agrícola. Então a instituição assume maior grau de importância e se eleva à altura das mais belas criações que é possível conceber" (MARANHÃO, 1859). Para justificar os gastos a serem feitos com a instalação da escola, afirma que a proteção e a educação desses meninos à custa dos cofres provinciais tinham sido uma experiência fecunda a partir de 1841 com a Revista HISTEDBR On-line, Campinas, n.48, p. 25-39 Dez.2012 - ISSN: 1676-2584 
criação e manutenção da Casa dos Educandos Artífices. Para ele, a educação profissional agrícola era a que mais carecia o Maranhão por permitir a adoção dos diversos meios empregados para sua vulgarização, pondo ao alcance de todos novas técnicas e instrumentos de lavrar, plantar e colher.

Essa importância atribuída à educação profissional agrícola era corroborada pelo Ministro da Agricultura, Comércio e Obras Públicas, Manoel Felizardo de Souza Mello, ao afirmar que essas instituições tinham a finalidade de animar, facilitar e dirigir o progresso e o desenvolvimento da agricultura. Do mesmo modo, Gonçalves Dias (1852), no Relatório sobre a Instrução Pública na Província do Norte e Nordeste, ao tratar da educação profissional como alternativa para uma possível saturação do mercado de trabalho para as carreiras de médicos, advogados e engenheiros, sugeriu ao governo central que

preparassem (os jovens) para a vida mecânica. Mas inteligente, e as outras materialmente produtivas, - de modo que se fosse trabalhando no desenvolvimento de nossa indústria e comércio e no aproveitamento dos recursos do nosso solo e produções. Em um quadro, em que tanto se fala em melhoramentos materiais, deveria ser dominante o pensamento destas criações, que só elas podem garantir o futuro desses projetados melhoramentos, se não queremos mendigar de contínuos recursos de inteligências estranhas, aproveitando homens no seu próprio país, menos habilitados para os empregos e trabalhos que em tanta seguridade lhes confiamos (DIAS, 1852).

Considerado um projeto moderno, civilizador e capaz de alavancar a inércia da lavoura, a Escola deveria adotar modelos agrícolas dos países em que a agricultura havia alçado níveis de desenvolvimento, a exemplo da França, Estados Unidos, Cuba e Antilhas, de onde deveriam ser importados equipamentos, máquinas, sementes e, principalmente, especialistas no método aratório. Outra possibilidade seria o governo conceder bolsas para jovens maranhenses estudarem nesses países.

O método aratório caracterizava-se pela substituição do trabalho humano por animais e de equipamentos manuais por máquinas no plantio, na colheita e no beneficiamento da produção. Dentre os gêneros a serem cultivados, predominavam aqueles que historicamente tinham sustentado a economia do Maranhão, desde a Colônia, como o algodão, a cana-deaçúcar, o arroz, seguido do milho, da mamona, do amendoim e do gergelim.

Paranaguá acreditava que as experiências agrícolas e pecuárias a serem desenvolvidas na escola poderiam contribuir para a melhoria das fazendas rurais, para a criação de novas raças de animais para o corte e leite em toda a Província, posto que "na atualidade e principalmente da instrução profissional que mais carece a lavoura da Província para tentar a adoção de novos processos de colheita até hoje inexperimentados e de todos os meios empregados para vulgarizá-los pondo-os ao alcance de todos, devem ser os objetivos da solicitude e dos esforços do governo" (MARANHÃO, 1859).

Para dar cabo a esse empreendimento, foi constituída uma Comissão Diretora formada pelos cidadãos Luiz Miguel Quadros, Raimundo Brito Gomes de Souza, Alexandre Theophilo de Carvalho Leal, Antonio Marques Rodrigues e José Ricardo Jauffret, que tinham a responsabilidade de estabelecer as diretrizes para o funcionamento da instituição; adquirir equipamentos e máquinas; requisitar junto ao governo os recursos humanos e financeiros; comprar e preparar o terreno, além de admitir os educandos.

$\mathrm{Na}$ falta de lugar próprio perto da capital com as condições para a instalação da Escola com salubridade, abundância de água e solo fértil, foram adquiridos dois amplos 
terrenos regados pelo Rio Cutim. O primeiro, denominado de Amaral, não tinha as acomodações prediais para alojar os funcionários e alunos, sendo propício apenas para o plantio. O segundo, chamado de Sampaio, de fácil acesso pelo Rio Anil e pelo Caminho Grande $^{3}$, era favorável para instalar os alojamentos, as oficinas e as aulas de primeiras letras. Sobre o terreno, a Comissão relata que "o estabelecimento assim organizado, em uma situação vantajosa, a beira de uma estrada do maior trânsito, à margem do Rio Cutim e na proximidade da capital, será franqueado às pessoas que quiserem visitá-lo e informar-se do seu estudo e do melhoramento do processo".

Se, por um lado, a Escola objetivava recolher os desvalidos de sorte, por outro lado, trazia uma forte esperança em melhorar o estado da lavoura por meio da educação profissional, substituindo os métodos tradicionais do lavrar, plantar e colher pelo método aratório. Para isso, era preciso formar mão-de-obra e uma das primeiras iniciativas do governo foi a concessão de auxílio aos lavradores Antônio Joaquim Lopes da Silva e José César Machado para estagiarem em fazendas agrícolas dos Estados Unidos e $\mathrm{Cuba}^{4}$. O primeiro iria aprender a cultura do algodão, arroz, milho e plantas similares, e o segundo, a cultura da cana e a fabricação do açúcar e aguardente. De igual modo, concedeu bolsas de estudos a jovens maranhenses para aprenderem agricultura na Europa que, ao retornarem, deveriam assumir o ensino agrícola na Escola do Cutim, a exemplo de Caetano Cândido Cantanhede, Ricardo Ernesto Ferreira de Carvalho e Joaquim Vianna Bayma ${ }^{5}$.

A partir de então, trazidos por esses lavradores e estudantes, adentraram na Província diversos instrumentos e máquinas agrícolas. Com a intenção de proporcionar uma maior dinâmica à produção agrícola, foi contratado, por um ano, o engenheiro mecânico norteamericano John Wetson para ensinar o plantio da cana e a fabricação do açúcar, a construção e a manutenção de máquinas a vapor.

Mesmo com os investimentos financeiros e humanos, a Escola não vinha apresentando os resultados esperados por causa da carência de especialistas no método aratório. Na perspectiva de sanar o problema, foi contratado nos Estados Unidos, em abril de 1859, o francês Luiz Clement para dirigir os trabalhos agrícolas da instituição e desenvolver a cultura do algodão, da cana-de-açúcar, do milho, do arroz, dentre outras, pelo sistema aratório. Além disso, deveria cuidar da escrituração da escola, tratar do gado, promover exposições dos produtos da Escola e outras atividades, de acordo com as ordens da Comissão Diretora. Também deveria atender, por ordem do presidente da Província, às fazendas particulares.

Apesar da sua vasta experiência, o diretor da Escola, José César Machado relatou em 1862 ao presidente da Província que "o francês Luiz Clement [...] não cuida de suas obrigações, passa muitas horas a dormir [...] quanto os serviços do campo estão demandando a sua presença, não admite reclamações a seus descuidos. Sai às noites do estabelecimento ao anoitecer e só volta as dez e doze horas". Além disso, aplicava castigos físicos aos alunos com as mãos e outras vezes com paus e chicotes; emprestava, sem ordens da direção, instrumentos aos lavradores da capital. Por fim, esse diretor alegou que o contratado desconhecia o que era o serviço aratório.

A acusação desse diretor era uma contradição, à medida que a nomeação de Clement resultou de sua indicação à Comissão Diretora, quando descreveu as qualidades e a competência profissionais do francês. As reclamações desse diretor contradizem também a opinião da Comissão Diretora que julgava o trabalho de Clement correspondente aos interesses e expectativas da instituição. Isso evidencia as lutas de poder no interior da Escola entre a Comissão e César Machado. A sua origem deve-se às acusações do diretor a José Caetano Vaz Júnior, presidente da Província, sobre o extravio dos livros de escrituração, o 
que inviabilizava inventariar o patrimônio adquirido pela mesma, o superfaturamento na compra e venda de instrumentos aos lavradores da Província e nos alimentos e vestuários dos educandos. Esse fato resultou na extinção da Comissão Diretora por esse presidente.

Esse jogo de acusações evidencia a fragilidade administrativa, financeira e educacional da Escola, o que motivou críticas na imprensa periódica local, quanto à sua efetividade frente aos gastos para sua manutenção, ou seja, implantar métodos modernos na lavoura maranhense e recolher e educar crianças órfãs. Como forma de reverter esse quadro de descrédito, foram criados os agentes protetores ${ }^{6}$ da Escola: lavradores do interior e da capital que tinham como missão promover subscrições e loterias para garantir a manutenção do ensino, a compra de sementes, instrumentos e máquinas agrícolas. Esses agentes acreditavam que a educação profissional oferecida no Cutim contribuiria para evitar a crescente decadência da agricultura e sua eminente aniquilação em toda a Província, pela deficiência de braços e capital, pela falta de vias de comunicação e o pelo predomínio do "sistema bárbaro" de lavrar, plantar e colher.

Para dar nova dinâmica à Escola, foi contratado, em 1863, Alexandre Etienne Durand como substituto de Luiz Clement. Era agrônomo com vasta experiência no sistema aratório e na direção da escola agrícola de Grigon (França). O relatório de Durand sobre o estado da Escola contradiz os apresentados pela Comissão e Diretores da Escola. Durand relatou que não era possível esperar bons resultados, pois o terreno era impróprio para a cultura agrícola, a não ser depois de longo tempo (cerca de uns quinze anos) e não havia trabalhadores para limpar constantemente o terreno das ervas daninhas. Em relação aos educandos, afirmou que eles desconheciam os fundamentos do método aratório, que alguns eram pequenos para o trabalho no campo e ainda não sabiam com proficiência as primeiras letras.

Em artigo publicado no Semanário do Maranhense, Carvalho, ao tratar do terreno em que fora instalado o estabelecimento do Cutim, afirmou que:

O arado só por si não conseguiria jamais mudar completamente a natureza d' aqueles terrenos tão compactos, porque, não interpondo-se, entre suas moléculas, nenhum corpo estranho, que as isolasse, e cessando a acção que as plantas, por meio de suas raízes, poderião sobre elles exercer - bastarião as chuvas do inverno para torná-los tão impermeáveis e rebeldes à cultura, como erão d'antes. Se, porém, depois de arado e revolvido o subsólo na profundidade conveniente, se lhes applicassem fortes doses de correctivos e estrumes, para em seguida amanha-los com frequiência e cuidado - lograr-sehia, sem duvidas, transforma-los em terra de não vulgar fecundidade" ( SEMINÁRIO MARANHENSE,1867, n.10)

Esse fato resultou no pedido de seu afastamento e nas primeiras indicações do encerramento da Escola por José Caetano Vaz Júnior, Presidente da Província.

Assim até hoje esta este estabelecimento em piores circunstâncias do que eram as em que o encontrei em julho do ano passado [1864], porque além da falta que, como então, aqui sentimos de pessoa profissional, que se encarregue de sua direção, está agora condenado, no local em que existe, por pessoa tão competente como não posso deixar de considerar a A. Durand. E depois, manter hoje aquele estabelecimento no Cutim seria no meu conceito condenar a Província ao estéril dispêndio de dez contos de reis anuais, que e por quanto tem regulado a respectiva despesa ordinária, não levando em conta a extraordinária que agora ele mesmo exige para a renovação da cerca, 
compra de instrumentos aratórios, animais, etc.

Se os resultados agrícolas não vinham apresentando os resultados esperados, em relação à educação dos jovens órfãos e desvalidos a situação eram a mesma, ou seja, não havia material adequado para o ensino das primeiras letras e espaços para as aulas.

\section{O ENSINO AGRÍCOLA NO CUTIM}

A educação agrícola no estabelecimento do Cutim não difere de outras instituições de educação profissional: todas apresentavam as mesmas características nos critérios de ingresso dos alunos, como a apresentação de certidão de pobreza e atestado de vacina. Em relação à idade, ao contrário da Casa de Aprendizes Artífices que admitiam crianças com a idade mínima de sete anos, na Escola do Cutim era exigido que fossem maiores de doze anos e menores de dezoito anos, quer os aprendizes subvencionados pela província, quer os aprendizes pensionistas internos. Estes, para serem admitidos, deveriam pagar a anuidade de cem mil réis, podendo ser afastados da Escola a qualquer tempo e sem restituição dos pagamentos recebidos.

Os subvencionados deveriam permanecer na instituição por cinco anos, período necessário para uma formação profissional agrícola. Todavia, poderiam ser despedidos por motivos como: moléstia incurável e procedimento mau e incorrigível, pelo que seriam entregues aos seus tutores ou pais e, caso fossem órfãos, seriam entregues aos juízes de órfãos para dar-lhes o destino que julgassem conveniente. Esse destino, habitualmente, era encaminhar para a guarda nacional ou para servirem de ajudantes de pedreiros, carpinteiros e em casas comerciais (caso apresentassem bons conhecimentos da leitura, escrita e cálculo).

As atividades dos alunos começavam às cinco horas da manhã; depois da revista eram encaminhados ao oratório para rezarem a Jesus, pela prosperidade do Brasil, do imperador, da família imperial e do estabelecimento. Os roteiros das orações eram os mesmos adotados na Casa dos Educandos Artífices e recitados antes do almoço, do jantar e da ceia. Após as orações, na varanda da Escola, os aprendizes seguiam para o campo até as 10 horas, quando assistiam às aulas de primeiras letras ${ }^{7}$ ministradas pelo professor Miguel Beckman que depois foi substituído por Daniel Rodrigues da Silva. No horário das aulas, eram ministrados os seguintes conteúdos: exercício de leitura, primeiro silenciosa e depois em voz alta, quando cada aluno lia um trecho do texto adotado pelo professor com a finalidade deste observar a pronúncia e pontuação; exercícios de escrita, através de cópias e ditados; o ensino das quatro operações era realizado em dias alternados e se constituía de exercício da tabuada, recitação em voz alta e realização de contas.

As aulas teóricas e práticas inerentes ao método aratório eram ministradas nas oficinas de carpina, ferreiro, criação de animais domésticos e plantio, colheita e beneficiamento dos produtos agrícolas. As aulas, nessas oficinas ao ar livre, eram ministradas em dois momentos. Em princípio, os alunos recebiam dos professores e mestres contratados, como John Watson, Luiz Clement e Alexandre Durand, fundamentos teóricos sobre a profissão do lavrador. Em seguida, no campo, exercitavam os ensinamentos ministrados no interior das oficinas. Essa ideia do ensino profissional teórico e prático foi defendida por Barroso (1867), quando afirmou que a educação para a indústria não poderia se restringir apenas a responder a determinadas condições manuais, mas era preciso que fosse acompanhada de reflexões sobre as atividades práticas exercitadas. De igual modo, Oliveira 
(1870) acreditava que somente um ensino profissional capaz de agregar os conhecimentos teóricos e práticos poderia fazer "os alunos acreditarem que o trabalho é uma redenção, pois por meio dele se educam e conquistam posições na sociedade".

Como todas as instituições de recolhimento e de educação profissional maranhense no Império, os atos disciplinares e de punição integravam o processo de ajustamento social e de ensino. Em relação à Escola do Cutim, toda e qualquer atividade deveria ser executada por ordem do diretor com prontidão e respeito. Um dos principais requisitos era o cuidado adequado com o vestuário que consistia em chapéu de palha, camisola e calça de pano azul de algodão e sapatos de pau ou tamancos, condição para o trabalho no campo, as aulas de primeiras letras, as oficinas e, principalmente, para saírem da escola. Uma das contravenções mais severas era a pronúncia de palavras ou gestos obscenos e desrespeito aos superiores professores, diretores e mestres das oficinas -, cujas punições eram: repreensão particular na secretaria; repreensão pública à frente do corpo de alunos formados; privação do recreio; exclusão da mesa por uma ou três vezes; supressão do nome do quadro de honra por um ou oito dias; prisão no xadrez da casa e a expulsão da Escola.

Na documentação pesquisada, especialmente os ofícios dos diretores aos presidentes de Província, localizamos inúmeras contravenções das ordens pelos educandos, desde brigas entre eles, até furto de roupas e outros objetos. Mas há um predomínio de fugas de aprendizes ou não retorno à instituição quando liberados para tratamento de saúde sob o cuidado dos pais ou tutores ou na enfermaria da Casa dos Educandos Artífices.

Ao contrário, os alunos que apresentavam bom comportamento e aprendizagem satisfatória eram recompensados com as seguintes menções:

a) Menção honrosa pela aplicação, aproveitamento ou moralidade, no quadro de honra;

b) Medalha de prata com a legenda: Escola Agrícola Maranhense - honra ao mérito;

c) Diploma assinado pelo diretor quando o aprendiz tiver concluído o aprendizado. No diploma serão mencionadas as recompensas alcançadas e os exames feitos;

d) Prêmios representados por instrumentos e livros agrícolas (REGULAMENTO da Escola, 1863).

Além desses problemas enfrentados pelos diretores para continuidade das atividades de ensino das primeiras letras e agrícola, os alunos frequentemente eram acometidos por moléstias, tais como as febres intermitentes. Não havia condições físicas e materiais para o desenvolvimento das atividades docentes e discentes. As aulas de primeiras letras eram ministradas na mesa onde eram servidas as refeições. Os materiais didáticos (cadernos, tinteiros, réguas e borrachas) eram insuficientes para os nove alunos, situação que levou o professor Miguel Beckman a pedir demissão. Outras matérias previstas no regulamento da Escola não foram implantadas (contabilidade agrícola, geografia agrícola do império e particularmente da Província) por dois motivos: a aprendizagem regular dos alunos nas primeiras letras e a carência de professores (REGULAMENTO, 1856).

Em consequência desses problemas, os exames anuais previstos no regulamento não ocorreram. A realização das exposições agrícolas (que deveriam ocorrer 7 de abril de cada ano em comemoração à data de criação da Escola) somente foi possível um ano antes de encerramento da instituição. Elas tinham a finalidade de divulgar os instrumentos agrícolas, os animais, plantas, cereais, frutos, legumes, flores e produtos como queijo, mant eiga e outros produtos da economia rural, cultivados no interior do estabelecimento. 
Ao contrário das oficinas em que os instrumentos, máquinas, sementes, plantas e animais atendiam em parte aos interesses do ensino profissional, o quadro era desanimador em relação às aulas das primeiras letras. A respeito do assunto, Fernando Luís Ferreira, diretor que substituiu José César Machado, reclamava que não era justo que os alunos tivessem condições para as aulas agrícolas, enquanto para as de primeiras letras não havia sequer cadeira, livros e tabuadas. Para ele, esse era o motivo de os alunos não aprenderem as "lições e as contas".

Sobre essa carência, Daniel Rodrigues da Silva, professor de primeiras letras, acrescentou que os alunos não aprendiam a ler, escrever e contar por não receberem uma alimentação adequada, a não ser farinha e carne, um pão pela manhã e à noite um mingau de arroz ou aveia, motivo pelo qual se queixavam de fome e, por isso, não tinham forças para contar e ler em voz alta. Ao contrário, os aprendizes conheciam e reproduziam os fundamentos religiosos como fazer o sinal da cruz e as primeiras orações de um cristão, o que evidencia a forte presença católica na instituição.

Outra crítica desse professor foi em relação às obras adquiridas para compor o acervo da biblioteca da Escola: todas em língua francesa, quando os alunos não sabiam sequer ler o alfabeto português. Ao analisarmos o catálogo dos livros adquiridos pela Comissão Diretora, a crítica desse professor foi confirmada.

Para a formação dessa biblioteca, justificava a Comissão Diretora ao presidente da Província João Lustosa Paranaguá:

Convencidos da necessidade de dotar a Escola de Aprendizes Agrícolas com uma biblioteca mandamos vir da França e recebemos 95 volumes de diversas obras modernas de agricultura, entre as quais as que mais recomendam pelo seu merecimento e acham-se depositadas na casa de um dos membros desta Comissão além de alguns volumes apresentados por particulares.

Quando a biblioteca foi instalada no interior da Escola, em 1863, foram incorporadas algumas obras em português, embora ainda predominassem os de língua francesa. $\mathrm{Na}$ listagem de livros, duas obras são de autoria e uma é traduzida por autores maranhenses: $O$ cultivo e o preparo do fumo (tabaco), de Sergio A. Vieira, Breves considerações sobre a nossa lavoura, de Fabio Alexandrino de Carvalho Reis e Plantador de algodão, de Turner, traduzido por A. Marques Rodrigues.

Esse é um dos exemplos da falta de política no Maranhão Imperial em relação ao desenvolvimento da agricultura e da educação profissional voltada para esse setor, fatores que iriam culminar com o encerramento da Escola Agrícola do Cutim em 1865.

Vários foram os motivos que contribuíram para o fim da instituição, dentre eles o dispêndio financeiro sem os resultados previstos quando da sua criação: ensinar o método aratório como mecanismos de melhoria da agricultura Provincial e formar trabalhadores para a lavoura. No período em que esteve em funcionamento, apenas catorze alunos ingressaram na Escola, todos com idade que não permitia condições físicas apropriadas para o trabalho agrícola.

Deduzimos que outro motivo tenha sido o desvio de recursos na compra e venda de instrumentos, sementes e animais pela Escola a fazendeiros locais e às inúmeras mudanças na direção da instituição e, principalmente, a pobreza do solo, que prescindia de amplos investimentos para torná-lo adequado para o plantio do algodão, milho, amendoim e arroz, por exemplo.

Com o encerramento de suas atividades, determinado por Ambrósio Leitão da 
Cunha, presidente de Província, os educandos que não tivessem outro destino além de serem entregues aos pais e tutores, deveriam ser recolhidos na Casa dos Educandos Artífices para aprenderem um dos ofícios ali ensinados. Os instrumentos e máquinas deveriam ser entregues a repartições de obras públicas e os animais leiloados.

Como afirma Marques (1970,p.263.), "infelizmente o resultado não foi correspondente ao fim da criação nem as enormes quantias despendidas com este estabelecimento quantias fabulosas e de forma alguma produtiva".

\section{OUTRAS TENTATIVAS DE EDUCAÇÃO AGRíCOLA}

Com o fim da Escola Agrícola do Cutim, por ordem do presidente da Província, foi criada na Casa dos Educandos Artífices (CEA), pela Lei n. 854, de 21 de junho de 1868, uma aula de agricultura teórica e prática, tendo o método aratório como o seu referencial metodológico. Essa aula havia sido proposta pelo presidente Eduardo Olímpio Machado à Assembleia Provincial em 1851, anterior à criação da Escola do Cutim. Na ocasião, afirmou que mesmo reconhecida a vantagem da Casa dos Educandos, esta poderia ter sido maior se no plano de sua organização fosse criada uma escola de agricultura, "pois sem dúvidas que precisamos muito de artífices destros e morigerados; porém, sobretudo, precisamos de agricultores inteligentes e práticos nos processos de roteamento e cultura usados nos países, cujas produções são idênticas às nossas, e que se acham mais do que nos adiantados" (MARANHÃO, 1851, p.17). Para formação do núcleo dessa escola deveriam ser escolhido os mancebos mais robustos que, divididos em duas turmas, se revezassem um dia na aprendizagem dos ofícios e, no outro, nas atividades agrícolas a serem ensinadas por um agricultor prático a ser contratado nas "Antilhas ou nos Estados do Sul da União-Americana para dirigir a escola " (MARANHÃO, 1851, p.18). Para efetivar o projeto, o governo deveria comprar um terreno próximo a CEA para implantá- $-{ }^{8}$

A lavoura e a Província, tão atrasada e rotineira, deve colher dessa escola grandes resultados, seja aprendendo a destocar e rotear a terra, a cultivar e beneficiar alguns produtos equinociais, que, com quanto de melhor qualidade, ainda estão longe de rivalizar com os produtos similares de outros países; seja obtendo para a administração de suas fazendas feitores inteligentes, bem morigerados e dotados além disto de conhecimento práticos de agricultura e de amor ao trabalho, nela adquirido (MARANHÃO, 1851, p.18).

Em 1866, a ideia dessa aula reacendeu com a Lei $n^{\circ} .773$, de 2 de julho de 1866 . Os defensores acreditavam que essa seria uma forma da CEA assumir a formação de aprendizes agrícolas, uma vez que a Escola do Cutim fechara em 1865. Essa lei, no seu artigo quinto, determinava:

Os quatro anos de reclusão estabelecidos no art. 1 da Lei N 541, de 30 de julho de 1859, para os que não forem dela dispensados por alguma disposição legislativa anterior a esta, serão preenchidos do seguinte modo. $\S 1 \mathrm{O}$ diretor da casa dos educandos se esforcara por fazer distribuir pelos melhores engenhos de açúcar desta província o número de educandos 
marcados no $\S 5$, a fim de serem aplicados na aprendizagem de plantio de cana e no fabrico de seus produtos.

$\S 2$ Os lavradores que reclamarem ou aceitarem educandos para seus estabelecimentos assinaram um termo, no qual se obriguem a dar-lhes alimentação, vestuário e uma gratificação razoável, que para os educandos machinistas nunca será inferior a cincoenta mil reis annuais.

§ 3 Antes de assignarem termo deverão os reclamantes impetrar do presidente da província licença, podendo cada lavrador receber dous educandos.

$\S 4$ No termo estabelecerá o diretor que seja nullo o contrato, caso não cumpra o lavrador com as condições assentadas, e nestas hypothese, voltarão os educandos a completar o tempo de reclusão, quando por ventura não tenha elle ainda expirado.

$\S 5$ Para o fim estabelecido no presente artigo serão destinados até quatorze educandos.

Isso fez com que, em 1868, fosse criada na CEA a aula de agricultura sob a regência do professor Ricardo Ernesto Ferreira de Carvalho. Em 1870, a aula era frequentada por onze educandos que, de acordo com o diretor Raimundo Jansen, "nada poderão eles aproveitar porque, sendo o curso mais pratico que teórico, não tem os alunos lugar próprio para praticarem as lições que recebem na aula". Entretanto, reconhecia a importância desse tipo de ensino, mas ao comparar com a finalidade da Casa o mesmo não tinha prioridade, "o que altamente atesta a queda de um estabelecimento bem montado como era a Escola Agrícola do Cutim".

Sugeriu a substituição dessa disciplina pela de língua francesa, matéria que o professor "era reconhecidamente distinto", idioma da maior importância, pois "em cujo dialeto existe tudo quanto de melhor se conhece nas artes". Desse modo, acreditava Raimundo Jansen Serra Lima "que seria mais bem aproveitando o sacrifício da província, si, em vez da aula de que trato, fosse estabelecida aqui a cadeira de língua francesa, e este magistério estou certo que o Dr.Carvalho nada deixaria a desejar".

Para José da Silva Maia, Presidente da Província, a aula de agricultura não teria resultado se continuasse a ser teórica: "não que julgue inconveniente os educandos possuírem [...] o conhecimento sobre a agricultura, mas sim porque o ensino agrícola, de que elles carecem deve ser inteiramente prático" (MARANHÃO, 1870, p. 24). Daí a sugestão de que essa aula fosse extinta e no seu lugar fosse criada uma escola de agricultura centrada no método aratório, puramente prático. Este Presidente retomou a proposta de Eduardo Olímpio Machado, de 1851, e de Paranaguá, de 1863.

Não haverá alli tempo perdido com os estudos de theoria, que depressa são esquecidos, sem que tenham jamais sido entendidos pelos alumnos. A frente do trabalho, ensinado com o exemplo, pondo em pratica aos olhos do aprendiz os processos hoje adaptados na agricultura europea e acompanhando a execução das explicações indispensáveis, o mestre de trabalho agrário chegará em pouco tempo a transmittir aos seus discípulos os conhecimentos de que elles carecem e que lhes bastam para poderem administrar vantajosamente os nossos estabelecimentos agrícolas (MARANHÃO, 1870, p. 24).

Sendo assim, o ensino seria obrigatório a todos os educandos que atingissem a idade de 15 anos e para aqueles que estivessem nos três últimos anos da sua estada no 
estabelecimento, "de modo que todos levem d'elle conhecimentos practicos de agricultura que mais tarde se tornarão de grande proveito para elles e para a província" (MARANHÃO, 1870, p. 24).

Essa aula foi extinta pela Lei $\mathrm{n}^{\circ} .890$, de 6 de julho de 1870, juntamente com a de ciências naturais e, por conseguinte, os lugares dos professores Francisco Antonio Brandão e Ricardo Ferreira de Carvalho, respectivamente; em seu lugar foi criada na CEA uma escola inteiramente prática de agricultura de acordo com as determinações de José da Silva Maia, presidente da Província.

Sendo o nosso país naturalmente agrícola e a lavoura a sua principal fonte de riqueza, parece é verdade, que a criação de uma escola prática de agricultura nesta casa seria de suma utilidade e vantagem para a província, onde o sistema aratório ainda não se acha convenientemente desenvolvido, como fora para desejar. Porem se por um lado é isto uma verdade incontestável, também por outro me parece que a criação de uma escola agrícola neste estabelecimento vai diretamente de encontro ao pensamento que presidiu a sua instituição, que só teve em vista criar uma escola de artes e ofícios e mecânicos para os infelizes desvalidos (MARANHÃO, 1870, p. 26)..

Sobre essa escola, Raimundo Jansen Pereira salientou que a única aula obrigatória a todos os educandos era a de primeiras letras, mesmo para aqueles alunos que não a freqüentavam:: "distrair, pois os educandos assim preparados para uma ocupação estranha a aquela, em que tem necessidade de desenvolver aperfeiçoar o seu adiantamento, importaria se isso se fechar essas oficinas, em pura perda de ensino já recebido e das rendas deste estabelecimento". Outra preocupação do diretor, por ser uma aula prática, era de ser realizada fora do âmbito da CEA, trazendo prejuízos na formação moral dos jovens e, por conseguinte, na moralidade da casa.

A ideia de criar uma escola agrícola para acolher meninos pobres e desvalidos para serem educados nos processos de "plantio,colheita das producções do solo, bem como dos meios de fertilisal-o, e onde ao mesmo tempo aprendessem os officios que são immediatos auxiliares da lavoura e tivessem educação moral e religiosa" (MARANHÃO, 1887, p. 19) não desvaneceu desde o fim da Escola Agrícola do Cutim que "infellizmente mallograda, entre outras causas por haver sido estabelecida em sitio muito próximo a capital, pouco fértil, quando deveria ser fundada no continente, onde o solo se prestaria mais facilmente aos processos modernos com os melhores resultados" (MARANHÃO, 1887, p. 19). Em 1887, José Bento de Araújo, na fala que dirigiu a Assembleia Provincial, assim se manifestou sobre a questão:

Revela aqui ponderar que si é útil à sociedade formar hábeis artistas, não o é menos à educação do homem do campo que, em um paiz agrícola como o nosso, concorrerá efficazmente para o seu engrandecimento e prosperidade. Convem preparar o menino de sorte que posa ser para o futuro um lavrador intelligente, e isso se conseguirá pelo ensino agrícola, pelos hábitos da vida rude, porém nobre e feliz do trabalho rural, longe da influencia perniciosa das cidades, onde a escassez dos meios de subsistência gera quase sempre vícios que rebaixam a dignidade do homem (MARANHÃO, 1887, p.19).

A fala de Bento de Araújo não difere de todas outras vozes sobre a importância do ensino agrícola para alavancar a lavoura maranhense em constante crise. A Escola do Cutim 
foi uma das mais significativas tentativas para animar o cultivo de variadas tipos de cultura agrícolas nos oitocentos. Contudo, diante dos fatos descritos no decorrer deste trabalho, os investimentos não surtiram os efeitos desejados pelos seus idealizados e pelos fazendeiros locais que esperavam implantar em suas terras métodos modernos para lavrar, plantar e colher.

A adoção do método aratório e a contratação de mão-de-obra estrangeira ou o envio de comissões e estudantes maranhenses aos países onde os processos de produção agrícola eram referência tornava-se uma possibilidade de colocar o Maranhão a frente de outras províncias e, por conseguinte, uma forma de garantir seu progresso econômico.

Ao mesmo tempo, a Escola vinha ao encontro de empreendimentos educacionais voltados para atender as crianças pobres e desvalidas como a Casa dos Educandos Artifices, o Asilo de Santa Teresa e a Escola de Aprendizes Marinheiros. Sendo a CEA o modelo adotado em todas as demais criadas no período.

Daí, com o fim da Escola do Cutim, a CEA tornou-se o local privilegiado para o ensino (teórico e prático) da agricultura na perspectiva de fazer da terra brotar a riqueza do Maranhão nos oitocentos, mas que infelizmente todas as tentativas não alcançaram os objetivos a que se propunham: animar a arte agrícola maranhense como acreditava Lustosa Paranaguá, em 1859.

\section{Referências}

BARROSO, José Liberato. A instrucção pública no Brasil. Rio de Janeiro. B. L. Garnier1867.

CASTRO, César Augusto. Infância e trabalho no Maranhão Provincial: uma história da Casa dos Educandos Artífices (1841-1889). São Luís: Fundação de Cultura, 2007.

Fontes e percursos para a história da educação. IN: CAVALCANTE, Maria Juraci Maia et AL. Estudos culturais: políticas, tempos e territórios de ações educacionais. Fortaleza: UFC, 2009.

CUNHA, Luis Antonio. O ensino de ofícios manufatureiros em arsenais, asilos e liceus. Forum Educacional, Rio de Janeiro, v.3, n.3, p.3-47, jul./dez., 1979.

DIAS, Gonçalves. Instrução pública em diversas províncias do Norte. In ALMEIDA, José Ricardo de. História da instrução pública no Brasil (1500-1889): história e legislação. São Paulo: EDUC, 1989.

KUHLMANN JÚNIOR, Moysés. Infância e Educação Infantil uma abordagem histórica. Porto Alegre: Mediação, 1998.

MARANHÃO. Relatório do Presidente da Província do MARANHÃO o doutor João Lustosa da Cunha Paranaguá, na abertura da Assembléia Legislativa Provincial no dia 3 de maio de 1859. MARANHÃO Typ. de J.M.C de Frias, 1959.

MARANHÃO. Fala dirigida pelo Exm. Presidente da Província do Maranhão, o Dr. Eduardo Olímpio Machado, à Assembléia Legislativa Província, por ocasião de sua instalação no dia 7 de setembro de 1851. Maranhão: Impresso na Typ. Constitucional de I.J.Ferreira,1851. 
MARANHÃO. Relatório com que o Excelentíssimo senhor vice-presidente da Província, Dr. José da Silva Maia, apresentação no dia 18 de maio de 1870 perante a Assembléia Legislativa Provincial, por ocasião da instalação de sua sessão ordinária. São Luiz do Maranhão, Typ. De J.M.A. Serrão, 1870.

MARANHÃO. Fala com que o Exm. Sr. Dr. José Bento de Araújo dirigiu a Assembléia Legislativa Provincial do Maranhão em 18 de março de 1887, por ocasião da instalação da 2a . Seção da 26ª legislativa. Maranhão. Typ. do Paiz,1897.

MARQUES, César Augusto. Dicionário histórico-geográfico da Província do Maranhão. Rio de Janeiro: Fon-Fon, 1970.

MESQUITA, Francisco de Assis Leal. Vida e morte da economia algodoeira do Maranhão. São Luis: EDUFMA, 1987.

MELlO, Luiz de. Cronologia das artes plásticas no Maranhão (1842-1930). São Luís: Litograf, 2004.

NASCIMENTO, Jorge Carvalho do. Problemas de método nos estudos sobre o ensino agrícola e o processo civilizador. Disponível em: <http://www.fef.unicamo.br; sipc;anais8;Jorge>. Acessado em: 14 maio 2008.

OLIVEIRA, A. de Almeida. O ensino público. Brasília, DF: Senado Federal, 2003.

REIS, Flávio. Grupos políticos e estrutura oligárquica no Maranhão. São Luís: [s. n.], 2007.

REGULAMENTO para a Escola Prática dos aprendizes agrícolas do Cutim. 6 set. 1856.

RODRIGUES, Antonio Marques. Duas palavras sobre a nossa agricultura com que abriu o livro manual do plantador de Turner. São Luiz: [S.N, 1959.

ROSA, Maria da Gloria de. História do ensino agrícola no Brasil República. Dissertação (Mestrado em Educação)- Universidade Estadual Paulista, Marília, São Paulo, 1980.

SEMANÁRIO MARANHENSE. São Luis, n.10, Edições SIOGE, 1979.

SILVA, José Ribamar Lima. O ensino secundário no Maranhão: o liceu como construtor de representações sociais de intelectuais. Dissertação ( Mestrado em Educação) - Universidade de São Paulo, 2007.

Notas

\footnotetext{
${ }^{1}$ Para José Ribamar Lima Silva, os estudos sobre a história da educação no Maranhão podem ser classificados em verticalizados e horizontalizados. O primeiro tipo se caracteriza pelos estudos que tratam especificamente de uma temática, por exemplo, as sobre o Liceu Maranhense. O segundo é constituído por trabalhos que abordam a
} 
história da educação, de maneira mais ampla, nos quais as instituições escolares são citadas e não analisadas com profundidade.

${ }^{2}$ Esta expressão é comum nos relatórios de presidentes de Província quando tratam das crianças de ambos os sexos atendidos pelos cofres provinciais.

${ }^{3}$ O Caminho Grande era a única via de comunicação terrestre entre a capital e o resto da Ilha de São Luís.

${ }^{4}$ Auxílio concedido pela Lei N. 447, de 7 de outubro de 1957, anterior a criação da Escola Agrícola do Cutim.

${ }^{5}$ Cf. Lei N. 758 de 14 de junho de 1866, da Província do Maranhão

${ }^{6}$ João José Corte Maciel (Icatu), Fernando Antônio dos Santos (Vargem Grande) e Lino Rodrigues (Brejo). Os da capital não foram localizados nas fontes pesquisadas.

${ }^{7}$ Os materiais escolares utilizados nessas aulas eram: tinteiros de estanho ou latão, lápis de louza, louza, papel em resma, cartilhas de a,b.c, catecismo, tabuadas e a gramática portuguesa.

${ }^{8}$ Podemos observar que as ideias de Olimpio Machado para a formação de uma Escola Agrícola não difere das colocadas em execução por Paranaguá em 1859 ao criar a Escola Agrícola do Cutim. 